\title{
Determinan Pengeluaran Rokok Elektrik di Kota Bandung
}

\section{Determinants of Electric Cigarette Spending in Bandung City}

\author{
Estro Dariatno Sihaloho ${ }^{1}$, Donny Hardiawan ${ }^{1}$, Mochamad Thoriq Akbar ${ }^{1}$, \\ Irlan Adiyatma Rum ${ }^{1}$, Adiatma Y.M.Siregar ${ }^{1}$ \\ ${ }^{1}$ Center for Economics and Development Studies, Departemen IImu Ekonomi, Universitas Padjadjaran \\ Korespondensi: Estro Dariatno Sihaloho, \\ e-mail: estro.sihaloho@unpad.ac.id
}

\begin{abstract}
Abstrak
Penelitian ini bertujuan untuk menganalisis faktor yang mempengaruhi pengeluaran rokok elektrik di Kota Bandung. Penelitian ini menggunakan Convenience Sampling dan formula Slovin, melakukan wawancara terhadap 200 pengguna rokok elektrik di Kota Bandung. Penelitian ini menggunakan metode Regresi Linear Berganda dengan STATA 12. Variabel yang digunakan adalah total pengeluaran rokok elektrik per bulan, harga alat mesin isap rokok elektrik, motivasi penggunaan rokok elektrik, jumlah rasa cairan rokok elektrik, pengetahuan mengenai resiko penggunaan rokok elektrik, dan status penggunaan ganda rokok konvensional dan rokok elektrik. Hasil regresi menunjukkan bahwa harga alat mesin isap rokok elektrik, motivasi penggunaan rokok elektrik, jumlah rasa cairan rokok elektrik berpengaruh positif dan signifikan pada peningkatan pengeluaran rokok elektrik di Kota Bandung. Sedangkan pengetahuan mengenai resiko penggunaan rokok elektrik tidak signifikan mengurangi tingkat pengeluaran rokok elektrik di kota Bandung. Penelitian ini juga menemukan bahwa status pengguna ganda rokok elektrik dan rokok konvensional berpengaruh negatif tetapi tidak signifikan pada pengeluaran rokok elektrik. Untuk mengurangi penggunaan rokok elektrik di Kota Bandung, pemerintah perlu meningkatkan kampanye kesehatan mengenai bahaya penggunaan rokok elektrik. Bahkan pemerintah seharusnya melarang penggunaan rokok elektrik karena pengaruh pengetahuan rokok elektrik yang tidak signifikan mengurangi konsumsi rokok elektrik.

Kata Kunci : Rokok Elektrik, Determinan Pengeluaran, Regresi Linear Berganda
\end{abstract}

\begin{abstract}
This research aims to analyze the factors that affect expenditure decision on electronic cigarettes in Bandung. This research uses the Convenience Sampling and Slovin formula, interviews 200 users of e-cigarettes in Bandung. This paper uses Multiple Linear Regression (MLR) with STATA 12. Total expenditure per month in electronic cigarettes, the price of electronic cigarette suction machine tools, motivation in using electronic cigarettes, the amount of electronic cigarettes liquid taste, knowledge about the risk of using electronic cigarettes, and the status dual user of conventional cigarettes and electronic cigarettes are has been used as variables in this research. The regression result shows that the price of electronic cigarettes, motivation to use electronic cigarettes, the amount of electronic cigarettes liquid taste are positively and significantly correlated with the total expenditure per month for electronic cigarettes in Bandung. In the other hand, knowledge about the risk of using electronic cigarettes not significantly reduces electronic cigarette expenditure. This study also finds that the status of dual users of electronic cigarettes and conventional cigarettes has a negative but not significant effect on electronic cigarette expenditure. To reduce the use of electronic cigarettes, the government needs to increase health campaigns regarding the dangers of electronic cigarettes. Even the government must bans the use of electronic cigarettes because knowledge about electronic cigarettes risk has insignificant effect to reduce consumption of electronic cigarettes.

Keywords: Electronic Cigarettes, Determinant of Expenditure, Multiple Linear Regression
\end{abstract}

\section{Pendahuluan}

Pengguna rokok elektrik di Indonesia meningkat secara signifikan. Survei Sosial Ekonomi Nasional (SUSENAS) tahun 2017 menunjukkan bahwa jumlah penduduk yang menggunakan rokok elektrik di Indonesia adalah sebanyak 4.419.622 orang (Badan Pusat Statistik 2017). Tabel 1 menunjukkan 10 provinsi dengan pengguna rokok elektrik terbanyak di Indonesia pada tahun 2017. Sebanyak $79,48 \%$ pengguna rokok elektrik di Indonesia berasal dari 10 provinsi ini. Jawa Barat menjadi provinsi dengan jumlah pengguna rokok elektrik terbanyak di Indonesia dengan jumlah pengguna sebesar 934.680 orang atau sebesar $21,15 \%$ dari total pengguna rokok elektrik nasional. 
Kota Bandung sebagai ibu kota dari Provinsi Jawa Barat menjadi salah satu kota di Indonesia dengan jumlah perokok elektrik terbesar di Indonesia. Terdapat 45.949 orang pengguna rokok elektrik di Kota Bandung pada tahun 2017 atau sebesar 4.92\% dari total pengguna rokok elektrik di Provinsi Jawa Barat atau sebesar 1,04\% dari total pengguna rokok elektrik di Indonesia.

Tabel 1. 10 Provinsi dengan pengguna rokok elektrik terbanyak tahun 2017(orang)

\begin{tabular}{llc}
\hline No & Provinsi & Jumlah Perokok Elektrik \\
\hline 1 & Jawa Barat & 934,680 \\
2 & Jawa Timur & 824,374 \\
3 & Jawa Tengah & 579,945 \\
4 & DKI Jakarta & 350,840 \\
5 & Banten & 256,430 \\
6 & Sumatera Utara & 166,110 \\
7 & Riau & 110,919 \\
8 & Sumatera Selatan & 105,282 \\
9 & Aceh & 95,492 \\
10 & Papua & 88,720 \\
\hline & Indonesia & $4,419,622$ \\
\hline
\end{tabular}

Sumber : SUSENAS 2017, diolah Penulis

Berbeda dengan rokok konvensional, rokok elektrik memiliki komponen yang lebih banyak. Agar dapat menggunakan rokok eletronik, seorang konsumen perlu memiliki mesin alat isap yang bertenaga baterai. Mesin bertenaga baterai ini digunakan untuk memanaskan cairan yang kebanyakan besar terbuat dari propilen glikol atau gliserol yang biasanya mengandung nikotin dan zat perasa (West and Brown 2014). Hal ini menjadikan jenis pengeluaran perokok elektrik sangat berbeda dengan perokok konvensional. Perokok elektrik memiliki 2 jenis pengeluaran yaitu pengeluaran awal untuk pembelian mesin alat isap dan pengeluaran habis pakai untuk pembelian cairan rokok elektrik. Sedangkan perokok konvensional hanya memiliki pengeluaran habis pakai yaitu pembelian rokok tembakau. Cairan rokok elektrik memiliki berbagai rasa. Berbeda dengan rokok konvensional, cairan rokok elektrik memiliki banyak rasa dan meningkatkan daya tarik konsumen muda untuk mencoba rokok elektrik (Dai and Hao 2016). Rokok elektrik berbeda dengan rokok konvensional karena penggunaan rokok elektrik harus menggunakan perangkat yang dapat menghasilkan uap yang mengandung nikotin (Drummond and Upson 2014). Drummond dan Upson (2014) menyampaikan bahwa penggunaan rokok elektrik meningkat secara pesat lintas negara dan secara global. Hal ini diakibatkan persepsi yang berkembang di kalangan anak muda yaitu penggunaan rokok elektrik lebih sehat dan bisa mengurangi ketergantungan terhadap tembakau (Drummond and Upson 2014).

Penggunaan rokok elektrik ternyata tidak hanya digunakan oleh pengguna rokok konvensional yang ingin berhenti menggunakan tembakau. Penggunaan rokok elektrik juga dilakukan oleh pengguna baru yang belum pernah mengkonsumsi tembakau dengan frekuensi rendah. Hal ini didorong karena adanya popularitas penggunaan rokok elektrik (Sussan et al. 2017). Terdapat banyak persepsi mengenai penggunaan rokok elektrik di Kota Bandung. Penelitian sebelumnya menemukan bahwa remaja memiliki anggapan bahwa penggunaan rokok elektrik lebih aman dibandingkan rokok konvensional (Jiang et al. 2019). Dengan anggapan ini, pengguna rokok elektrik bisa berhenti menggunakan rokok konvensional. Penelitian sebelumnya juga menemukan bahwa pengguna rokok konvensional di Kota Bandung mulai mencoba mengkonsumsi rokok elektrik karena beranggapan bahwa penggunaan rokok elektrik lebih sehat dibandingkan dengan rokok konvensional meskipun belum pernah mencari informasi kesehatan yang benar (Sihaloho and Rum 2017).

$$
\text { Pengetahuan kesehatan mengenai }
$$
penggunaan rokok elektrik masih cukup rendah. Penelitian di Mesir menunjukkan bahwa lebih dari setengah $(57,5 \%)$ responden pernah mendengar mengenai rokok elektrik, 51,8\% diantaranya adalah bukan perokok elektrik. Di antara mereka, 41,6\% meyakini bahwa rokok elektrik mengurangi 
kecanduan rokok dan 31,9\% percaya bahwa rokok elektrik lebih tidak berbahaya dibandingkan rokok konvensional (Abo-Elkheir and Sobh 2016). Bahkan staff kesehatan pun masih memiliki pengetahuan yang rendah mengenai rokok elektrik. Dari 256 staff kesehatan yang diwawancarai lintas negara di Eropa (Dominan 26,7\% Italia, 16,9\% Spanyol, dan $16,5 \%$ Portugal) ditemukan pengetahuan mengenai bahaya rokok elektrik belum optimal (Ferrara et al. 2019). Penelitian lain menunjukkan bahwa 39\% mahasiswa kedokteran di Karachi, Pakistan meyakini bahwa rokok elektrik lebih tidak berbahaya dibandingkan rokok tembakau (Iqbal et al. 2017). Namun berdasarkan bukti yang telah dikumpulkan, rokok elektrik tidak bebas emisi seperti yang diyakini sebagian orang karena rokok elektrik juga mengeluarkan berbagai bahan kimia berbahaya dan beracun bagi tubuh (Qasim et al. 2017). Dari penelitian klinis yang dilakukan pada 53 pengguna rokok elektrik sebagian besar pengguna mengalami gejala pernafasan sebanyak $98 \%$, gejala gastrointestinal sebanyak $81 \%$ dan gejala konstitusionl sebanyak 100\% (Layden et al. 2019).

Pengeluaran rokok elektrik menjadi pengukuran paling tepat untuk mengukur intensitas penggunaan rokok elektrik (Yao et al. 2017). Bahkan Yao (2017) menemukan hubungan yang positif atarara pengeluaran rokok dengan gejala sesak napas pada 533 responden yang di teliti. Pengeluaran rokok elektrik dipengaruhi oleh berbagai faktor seperti total permintaan cairan rokok elektrik (Stein et al. 2018). Stein et al (2018) menyimpulkan bahwa perokok elektrik memiliki demand yang tinggi terhadap cairan rokok elektrik ditunjukkan dengan intensitas pembelian cairan rokok elektrik. Stein et al (2018) juga menemukan ketergantungan rokok elektrik yang lebih besar dikaitkan dengan elastisitas harga rokok elektrik yang lebih rendah. Berdasarkan hal tersebut ada kesenjangan berkaitan dengan pengaruh berbagai faktor di atas terhadap pengeluaran rokok elektrik.

Peningkatan kesadaran mengenai penggunaan rokok elektrik telah didokumentasikan di negaranegara berpenghasilan tinggi. Tetapi negara berpenghasilan menengah dan rendah masih memiliki data yang buruk mengenai pengguna rokok elektrik (Palipudi et al. 2016). Kondisi ini juga terjadi di Indonesia pada umumnya dan Kota Bandung pada khusus nya karena data mengenai pengguna rokok elektrik belum memadai. Survei Sosial Ekonomi Nasional (SUSENAS) yang dilakukan oleh Badan Pusat Statistik pada tahun 2017 hanya memiliki pertanyaan mengenai penggunaan rokok elektrik yakni apakah selama sebulan terakhir respoden menggunakan rokok elektrik. Pilihan jawaban dari pertanyaan ini adalah :(1) Ya, setiap hari, (2) Ya, tidak setiap hari, (5) Tidak, dan (8) Tidak tahu. Survei skala nasional belum memiliki data mengenai jenis pengeluaran dalam mengkonsumsi rokok elektrik.

Penelitian ini bertujuan untuk menganalisis faktor apa saja yang mempengaruhi besar pengeluaran rokok elektrik di Kota Bandung. Pengeluaran rokok elektrik yang lebih besar mengindikasikan konsumsi rokok elektrik yang lebih banyak. Penggunaan rokok elektrik yang tidak terkendali akhirnya akan melahirkan masalahmalasah kesehatan. Penelitian ini akan berguna untuk kebijakan pengendalian rokok dan intervensi kesehatan masyarakat di Kota Bandung.

\section{Metode Penelitian}

Penelitian ini menggunakan data primer dengan melakukan wawancara langsung pengguna rokok elektrik di Kota Bandung pada tahun 2017. Berikut adalah deskripsi variabel pada penelitian ini: 
Tabel 2. Deskripsi Variabel Penelitian

\begin{tabular}{|c|c|c|c|c|}
\hline \multirow{2}{*}{$\begin{array}{l}\text { Variabel } \\
\text { Variabel Dependen }\end{array}$} & \multirow[t]{2}{*}{ Pertanyaan } & \multicolumn{2}{|c|}{ Kategori } & Frekuensi \\
\hline & & & & (Orang) \\
\hline \multirow[t]{7}{*}{$\begin{array}{l}\text { Pengeluaran Rokok } \\
\text { Elektrik }\end{array}$} & \multirow{7}{*}{$\begin{array}{l}\text { Berapa besar belanja cairan } \\
\text { rokok elektrik per bulan? } \\
\text { (Rupiah) }\end{array}$} & Min & 40.000 & \multirow{7}{*}{200} \\
\hline & & Max & 1.155 .000 & \\
\hline & & Mean & 292.100 & \\
\hline & & Std. Dev & 206.025 & \\
\hline & & Kuartil 1 & 150.000 & \\
\hline & & Kuartil 2 & 230.000 & \\
\hline & & Kuartil 3 & 400.000 & \\
\hline \multicolumn{5}{|l|}{ Variabel Independen } \\
\hline \multirow{7}{*}{$\begin{array}{l}\text { Harga Alat Isap Rokok } \\
\text { Elektrik }\end{array}$} & \multirow{7}{*}{$\begin{array}{l}\text { Berepa harga alat isap rokok } \\
\text { elektrik yang anda gunakan? } \\
\text { (Rupiah) }\end{array}$} & Min & 300.000 & \multirow[t]{7}{*}{200} \\
\hline & & $\operatorname{Max}$ & 6.550 .000 & \\
\hline & & Mean & 1.070 .475 & \\
\hline & & Std. Dev & 769.739 & \\
\hline & & Kuartil 1 & 550.000 & \\
\hline & & Kuartil 2 & 900.000 & \\
\hline & & Kuartil 3 & 1.300 .000 & \\
\hline \multirow[t]{2}{*}{ Motivasi Penggunaan } & \multirow[t]{2}{*}{$\begin{array}{l}\text { Apa motivasi anda } \\
\text { menggunakan rokok elektrik? }\end{array}$} & \multicolumn{2}{|c|}{$\begin{array}{l}1 \text { (Agar berhenti } \\
\text { merokok konvensional) }\end{array}$} & 108 \\
\hline & & \multicolumn{2}{|c|}{0 (Alasan Lainnya) } & 92 \\
\hline \multirow[t]{7}{*}{ Jumlah Rasa Cairan } & \multirow{7}{*}{$\begin{array}{l}\text { Berapa jumlah cairan rokok } \\
\text { elektrik yang anda gunakan } \\
\text { dalam satu bulan? } \\
\text { (Botol) }\end{array}$} & 1 rasa & & 77 \\
\hline & & 2 rasa & & 66 \\
\hline & & 3 rasa & & 32 \\
\hline & & 4 rasa & & 11 \\
\hline & & 5 rasa & & 9 \\
\hline & & 6 rasa & & 2 \\
\hline & & 7 rasa & & 3 \\
\hline \multirow[t]{2}{*}{ Pengetahuan Resiko } & \multirow{2}{*}{$\begin{array}{l}\text { Apakah anda mengetahui resiko } \\
\text { dari penggunSaan rokok } \\
\text { elektrik? }\end{array}$} & 1 (Iya) & & 79 \\
\hline & & 0 (Tidak) & & 121 \\
\hline \multirow[t]{2}{*}{$\begin{array}{l}\text { Penggunaan Ganda } \\
\text { Rokok Konvensional } \\
\text { dan Rokok Elektrik }\end{array}$} & $\begin{array}{l}\text { Apakah setelah anda } \\
\text { menggunakan rokok elektrik, } \\
\text { anda masih menggunakan rokok } \\
\text { konvensional? }\end{array}$ & 1 (Iya) & & \multirow[t]{2}{*}{117} \\
\hline & & 0 (Tidak) & & \\
\hline
\end{tabular}


Penetuan jumlah sample dalam penelitian ini menggunakan metode sampling Slovin (1960) yaitu :

$$
n=\frac{N}{1+N e^{2}}
$$

Dimana $\mathrm{N}$ adalah jumlah populasi sedangkan e adalah margin dari error (Tejada and Punzalan 2012). Penelitian ini menggunakan margin error sebesar $10 \%$. Jumlah populasi perokok elektrik pada tahun 2017 di kota Bandung adalah 45.949 orang sehingga diperoleh jumlah sampel sebesar 99,78 dibulatkan menjadi 100 orang. Tetapi penelitian ini melakukan wawancara hingga 200 orang perokok elektrik sehingga margin error nya berkurang dari $10 \%$ menjadi $7.05 \%$. Pemilihan responden dilakukan dengan cara Convenience Sampling (Etikan, Musa, and Alkassim 2016). Metode ini merupakan jenis dari non-probability or non-random sampling sehingga metode ini dapat melakukan wawancara pada sampel secara random dengan kriteria aksesibilitas mudah dan kedekatan geografis. Responden yang diwawancarai juga memiliki waktu dan bersedia berpartisipasi dimasukkan ke dalam penelitian (Etikan, Musa, and Alkassim 2016). Aksesibiltias yang mudah pada komunitas pengguna rokok elektrik dapat ditemukan di kafe-kafe di Kota Bandung dan melakukan wawancara hampir keseluruhan di kafe-kafe di Kota Bandung. Wawancara dilakukan secara langsung melalui tatap muka antara peneliti dengan pengguna rokok elektrik. Jenis wawancara yang dilakukan adalah wawancara tertutup dengan merahasiakan nama dan informasi mengenai narasumber.

Model regresi yang digunakan dalam penelitian ini adalah Multiple linear regression (MLR). Model regresi linear berganda digunakan untuk menganalisis hubungan sebuah variabel dependen dan lebih dari satu variabel independen (Greene 2012). Data yang digunakan adalah cross-section yang diolah menggunakan STATA 12. Model regresi linear berganda yang digunakan dalam penelitian ini adalah :

$$
\begin{array}{r}
\widehat{P R E}=\alpha_{1}+\alpha_{2} H A I R E_{i}+\alpha_{3} M P_{i}+\alpha_{4} J R C_{i} \\
+\alpha_{5} P R_{i}+\alpha_{6} P R K_{i}+U_{i}
\end{array}
$$

Dimana :

PRE adalah Pengeluaran Rokok Elektrik Bulanan (Rupiah)

HAIRE adalah Harga Alat Isap Rokok Elektrik (Rupiah)

MP adalah Motivasi Penggunaan Rokok Elektrik

JRC adalah Jumlah Rasa Cairan Rokok Elektrik

PR adalah Pengetahuan Resiko Rokok Elektrik

PRK adalah Status Penggunaan Ganda Rokok Konvensional dan Rokok Elektrik

\section{Hasil Penelitian}

Dengan menggunakan Multiple linear regression (MLR) pada data 200 data responden pengguna rokok elektrik di kota Bandung, berikut adalah kaitan antara variabel bebas terhadap variabel terikat :

Tabel 3. Hasil Multiple linear regression (MLR)

\begin{tabular}{lc}
\hline Variabel & \\
\hline Harga Alat Isap Rokok & $0,0484 * * *$ \\
Elektrik & $(2,82)$ \\
Motivasi Penggunaan & $19.578 *$ \\
Rokok Elektrik & $(1,67)$ \\
Jumlah Rasa Cairan Rokok & $140.094,7 * * *$ \\
Elektrik & $(19,78)$ \\
Pengetahuan Resiko Rokok & $-10.474,9$ \\
Elektrik & $(-0,84)$ \\
Status Penggunaan Ganda & $-10.248,6$ \\
Rokok Konvensional dan & $(-0,9)$ \\
Rokok Elektrik & \\
$*$ p < 0.1, ** p < 0.05, *** p < 0.01 & \\
Sumber : Pengolahan Data, STATA 12 & \\
\end{tabular}

Penelitian ini telah menggunakan robust pada model regresi linear berganda yang digunakan. Analisis regresi robust menjadi solusi untuk regresi linear agar terhindar dari masalah asumsi klasik (Rasheed et al. 2014). Dengan penggunaan 
regresi robust akan menciptakan model terbaik dan stabil (Thoni et al. 1990). Metode regresi robust menjadi solusi dan menghindari penyimpangan yang terjadi pada model dan dapat digunakan sebagai pengganti metode kuadrat terkecil (Draper and Smith 2014).

Hasil regresi menunjukkan bahwa terdapat 3 variabel yang berpengaruh positif dan signifikan pada pengeluaran konsumen rokok elektrik di kota Bandung yaitu harga alat isap rokok elektrik, motivasi penggunaan rokok elektrik dan jumlah rasa cairan rokok elektrik. Sedangkan variabel yang berpengaruh negatif adalah pengetahuan resiko rokok elektrik dan status penggunaan rokok konvensional setelah menggunakan rokok elektrik

\section{Pembahasan}

Hasil regresi menunjukkan beberapa variabel bebas memiliki berpengaruh positif terhadap pengeluaran rokok elektrik dalam sebulan sedangkan beberapa varibel bebas memiliki pengaruh negatif. Salah satu variabel bebas yang memiliki pengaruh positif terhadap jumlah pengeluaran rokok elektrik seseorang adalah harga alat isap rokok elektrik. Variabel ini memiliki pengaruh yang signifikan. Dari responden yang diwawancarai, harga alat isap rokok elektrik bervariasi dari yang paling rendah seharga Rp 300.000 hingga yang paling mahal seharga Rp 6.550.000. Hasil regresi menunjukkan peningkatan harga alat isap rokok elektrik sebesar 1 Rupiah akan meningkatkan pengeluaran bulanan rokok elektrik sebesar Rp 0,048 . Hasil wawancara menunjukkan konsumen yang memiliki alat isap yang lebih mahal cenderung lebih sering mengkonsumsi rokok elektrik. Hal ini disebabkan alat isap yang lebih mahal memiliki kualitas yang lebih baik dan nyaman untuk digunakan. Cheng et all (2019) juga menemukan bahwa untuk pembelian alat isap elektronik meningkatkan pengeluaran rokok elektronik terutama di awal penggunaan. Penelitian yang dilakukan di Inggris, Amerika
Serikat, Kanada, dan Australia menemukan bahwa alat isap rokok elektrik lebih mahal hingga 5 kali dari harga satu bungkus rokok konvensional (Cheng et al. 2019)

Variabel motivasi penggunaan rokok elektrik juga memiliki pengaruh positif dan signifikan terhadap jumlah pengeluaran rokok elektrik per bulannya. Sebanyak 108 orang responden atau sebesar 54\% menggunakan rokok elektrik agar dapat berhenti merokok konvensional. Responden dengan motivasi agar dapat berhenti merokok konvensional memiliki pengeluaran rokok elektrik bulanan lebih besar Rp 19.578 dibandingkan motivasi lainnya. Penelitian sebelumnya di Barcelona, Spanyol pada tahun 2015 menunjukkan hanya $40.23 \%$ responden yang menggunakan rokok elektrik agar berhenti merokok konvensional, hal ini menjadikan konsumsi rokok elektrik menjadi lebih banyak (Bunch et al. 2018). Konsumsi yang lebih banyak akan mendorong pengeluaran yang lebih tinggi. Sekitar $46 \%$ dari responden memiliki tujuan bukan untuk berhenti merokok konvensional. 46\% lainnya memiliki alasan mengkonsumsi rokok elektrik yaitu memiliki banyak rasa $(18.5 \%)$, coba-coba $(12 \%)$, lagi trending $(6 \%)$, ekonomis/pengeluaran menjadi lebih sedikit (5\%), dan alasan lainnya (4.5\%).

Data responden menunjukkan bahwa sekitar $18,5 \%$ responden memiliki tujuan utama mengkonsumsi rokok elektrik karena rokok elektrik memiliki banyak rasa. Jadi perokok elektrik akan cenderung mencoba banyak rasa cairan rokok elektrik. Hasil regresi menunjukkan bahwa jumlah rasa yang dikonsumsi perokok elektrik berpengaruh positif dan sangat signifikan terhadap pengeluaran rokok elektrik. Penambahan 1 jenis rasa yang dikonsumsi akan menambah pengeluaran rokok elektrik sebesar Rp 140.095 dalam satu bulan. Hasil regresi menunjukkan bahwa terdapat 3 faktor yang dapat meningkatkan pengeluaran rokok eletronik bulanan dan faktor terbesar nya adalah jumlah rasa rokok elektrik yang dikonsumsi. Hasil 
wawancara menunjukkan konsumen rokok elektrik kebanyakan besar menggunakan 1 rasa sebesar 39\% atau 77 orang responden dan penggunaan 2 rasa sebesar 33\% atau 66 orang responden. Namun tidak sedikit perokok elektrik yang menggunakan lebih dari 2 rasa. Dari 200 responden yang diwawancarai langsung, terdapat $16 \%$ responden yang mengkonsumsi 3 rasa, $6 \%$ responden yang mengkonsumsi 4 rasa, 5\% responden yang mengkonsumsi 5 rasa. Bahkan terdapat responden yang mengkonsumsi 6 rasa $(0.5 \%)$ dan 7 rasa (1.5\%) dalam setiap bulannya. Hal ini pastinya akan mempengaruhi tingkat pengeluaran yang berbeda-beda pada tiap responden.

Penelitian ini menemukan beberapa variabel yang dapat mengurangi pengeluaran rokok elektrik yaitu pengetahuan mengenai resiko rokok elektrik dan status penggunaan ganda rokok konvensional dan rokok elektrik. Pengeluaran rokok elektrik akan lebih kecil Rp 10.475 kalau pengguna rokok eletronik mengetahui mengenai resiko dari rokok elektrik. Dari 200 responden yang diwawancarai, hanya terdapat $39,5 \%$ atau 79 orang yang mengaku mengetahui resiko penggunaan rokok elektrik sedangkan 121 orang lainnya atau $60.5 \%$ mengaku tidak mengetahui sama sekali resiko dari penggunaan rokok elektrik. Namun pengetahuan mengenai resiko penggunaan rokok elektrik tidak signifikan pada pengurangan konsumsi rokok eletronik. Saat ini penelitian medis yang memaparkan resiko penggunaan rokok elektrik sudah banyak dilakukan. Penelitian sebelumnya menunjukkan bahwa penggunaan rokok elektrik dapat menyebabkan peradangan, stres oksidatif, dan ketidakseimbangan hemodinamik yang mengarah pada peningkatan risiko penyakit kardiovaskular (Buchanan et al. 2019). Efek buruk terhadap sistem kardiovaskular, angiogenesis, dan perfusi kapiler kulit berakibat fatal karena menimbulkan cedera langsung pada dinding pembuluh darah, peningkatan agregasi trombosit, trombosis mikrovaskuler dan peradangan (Reinikovaite et al. 2018). Penggunaan rokok elektrik juga mengakibatkan peningkatan keterlambatan pemulihan dari infeksi pernapasan (Gotts et al. 2019). Pengetahuan rendah mengenai resiko penggunaan rokok elektrik juga tidak diiringi oleh kemauan pengguna rokok elektrik untuk memeriksakan kesehatan. Pada penelitian yang dilakukan di Inggris Raya dengan menganalisis 1489 responden pada tahun 2016 menunjukkan bahwa hanya terdapat $8.7 \%$ responden yang berhenti menggunakan rokok elektrik dan akhirnya mengurangi pengeluaran karena pengetahuan tentang resiko rokok elektrik (Simonavicius et al. 2017).

Penelitian ini menunjukkan bahwa pengguna rokok elektrik yang masih menggunakan rokok konvensional atau menjadi pengguna rokok ganda memiliki pengeluaran rokok elektrik yang lebih rendah sebesar Rp 10.249. Sarah et all (2019) menemukan bahwa pengguna ganda rokok elektrik dan konvensional masih memiliki pengeluaran rokok konvensional yang jauh lebih besar dibandingkan rokok elektrik. Hal ini menunjukkan penggunaan rokok ganda akan lebih cenderung mengurangi pengeluaran roko elektrik dibanding rokok konvensional. Dari 200 responden yang diwawancarai, ternyata responden yang masih menggunakan rokok elektrik secara bersamaan dengan penggunaan rokok konvensional masih lebih banyak. Terdapat 58,5\% atau sebanyak 117 orang yang menggunakan rokok elektrik dan konvensional secara bersamaan. Penelitian sebelumnya menunjukkan bahwa mahasiswa di Kota Bandung yang menggunakan rokok elektrik cenderung tidak bisa lepas dari penggunaan rokok konvensional dan akhirnya menjadi pengguna rokok ganda (Sihaloho and Tambak 2020). Hal ini juga didukung oleh data Susenas 2017 yang menunjukkan bahwa total pengguna ganda rokok elektrik dan konvensional di Indonesia pada tahun 2017 sebesar 4,280,808 
orang atau sebesar $97 \%$ dari perokok elektrik. Data ini menunjukkan hanya 3\% perokok elektrik yang berhenti menggunakan rokok konvensional. Penggunaan rokok elektrik dan rokok konvensional secara bersamaan memiliki dampak yang lebih buruk. Penelitian sebelumnya menunjukkan jika seorang perokok elektrik masih mengkonsumsi rokok konvensional secara bersamaan maka akan meningkatkan resiko stroke dengan sangat tinggi (Parekh, Pemmasani, and Desai 2020).Dampak kesehatan yang lebih buruk akan berakibat lebih buruk terhadap perekonomian.

Kebijakan pengendalian rokok elektrik saat ini di Indonesia masih sangat minim. Peraturan terkait dengan rokok elektrik masih sebatas peraturan yang berkaitan dengan cukai rokok elektrik yaitu Peraturan Menteri Keuangan (PMK) Nomor 146/PMK.010/2017 dan Peraturan Menteri Keuangan Nomor 152/PMK.010/2019 (Kementerian Keuangan 2017; Kementrian Keuangan 2019). PMK terbaru merevisi peraturan sebelumnya dengan menaikkan cukai rokok elektrik sebesar $25 \%$. Hingga tahun 2020, Kementrian Kesehatan dan BPOM belum memiliki peraturan mengenai penggunaan rokok elektrik di Indonesia, tetapi sudah memiliki penelitian-penelitian terkait dengan bahaya rokok elektrik. Data Susesnas 2017 menunjukkan bahwa kemungkinan perokok elektrik menjadi perokok ganda sangat besar yaitu 96,85\%. Hal ini menunjukkan kerugian kesehatan dan kerugian ekonomi yang akan ditimbulkan perokok ganda akan semakin besar. Sudah seharusnya pemerintah memiliki peraturan yang jelas mengenai penggunaan rokok elektrik di Indonesia yang dituangkan dalam perundangundangan secara tegas melarang penggunaan rokok elektrik. Pemerintah juga dapat menaikkan cukai rokok elektrik hingga ratusan persen untuk mengurangi konsumsi rokok elektrik di Indonesia. Saat ini WHO sudah memberikan rekomendasi untuk menghentikan penggunaan rokok elektrik. WHO melaporkan bahwa
Finlandia berhasil mengurangi angka perokok tanpa adanya lonjakan perokok elektrik dengan adanya peraturan yang kuat (World Health Organization 2020). Pada tahun 2016, FDA (Food and Drug Administration) Amerika Serikat mulai membuat aturan ketat terhadap penggunaan rokok elektrik di Amerika Serikat. Bahkan terdapat negara bagian di Amerika Serikat yang telah melarang penggunaan semua jenis tembakau termasuk rokok elektrik (Lichtenberg 2017)

\section{Kesimpulan dan Saran \\ Kesimpulan}

Pengeluaran rokok elektrik menjadi salah satu indikator intensitas penggunaan rokok elektrik. Semakin tinggi pengeluaran rokok elektrik, semakin tinggi konsumsi rokok elektrik seseorang. Penggunaan yang semakin sering akan meningkatkan resiko pengguna rokok elektrik terkena penyakit penyakit dan akan menimbulkan beban kesehatan dan beban ekonomi bagi negara. Hasil regresi menunjukkan bahwa harga alat mesin isap rokok elektrik, motivasi penggunaan rokok elektrik, jumlah rasa cairan rokok elektrik berpengaruh positif dan signifikan pada peningkatan pengeluaran rokok elektrik di Kota Bandung. Sedangkan pengetahuan mengenai resiko penggunaan rokok elektrik dan status penggunaan rokok konvensional setelah menggunakan rokok elektrik berpengaruh negatif tetapi tidak signifikan pada pengeluaran rokok elektrik di Kota Bandung.

\section{Saran}

Hasil penelitian ini dapat menjadi rekomendasi kepada pemerintah Kota Bandung secara khusus dan pemerintah pusat secara tegas melarang penggunaan rokok elektrik.

\section{Daftar Pustaka}

Abo-Elkheir, Omaima I., and Eman Sobh. 2016. "Knowledge about Electronic Cigarettes and Its Perception: A Community Survey, Egypt.” Respiratory Research. 
Badan Pusat Statistik. 2017. "Survei Sosial Ekonomi Nasional 2017." SocioEconomic/Monitoring Survey.

Buchanan, Nicholas D et al. 2019. "Cardiovascular Risk of Electronic Cigarettes: A Review of Preclinical and Clinical Studies." Cardiovascular Research 116(1): 40-50. https://doi.org/10.1093/cvr/cvz256.

Bunch, Kailey et al. 2018. "Motivation and Main Flavour of Use, Use with Nicotine and Dual Use of Electronic Cigarettes in Barcelona, Spain: A Cross-Sectional Study." BMJ Open 8(3).

Cheng, Kai Wen et al. 2019. "Prices, Use Restrictions and Electronic Cigarette UseEvidence from Wave 1 (2016) US Data of the ITC Four Country Smoking and Vaping Survey." Addiction.

Dai, Hongying, and Jianqiang Hao. 2016. "Flavored Electronic Cigarette Use and Smoking among Youth." Pediatrics 138(6).

Draper, Norman R., and Harry Smith. 2014. "Applied Regression Analysis, 3rd Edition." John Wiley \& Sons.

Drummond, M. Bradley, and Dona Upson. 2014. "Electronic Cigarettes: Potential Harms and Benefits." Annals of the American Thoracic Society.

Etikan, Ilker, Sulaiman Abubakar Musa, and Rukayya Sunusi Alkassim. 2016. "Comparison of Convenience Sampling and Purposive Sampling." American journal of theoretical and applied statistics 5(1): 1-4.

Ferrara, Pietro et al. 2019. "Knowledge about ECigarettes and Tobacco Harm Reduction among Public Health Residents in Europe." International Journal of Environmental Research and Public Health.

Gotts, Jeffrey E, Sven-Eric Jordt, Rob McConnell, and Robert Tarran. 2019. "What Are the Respiratory Effects of ECigarettes?" BMJ 366: 15275. http://www.bmj.com/content/366/bmj.1527 5.abstract.

Greene, WH William H . 2012. Prentice Hall Econometric Analysis 7th Ed.

Iqbal, Nousheen et al. 2017. "Prevalence and Knowledge of Electronic Cigarettes amongst Medical Students, A Cross Sectional Survey from Karachi, Pakistan." European Respiratory Journal 50(suppl 61): PA4487. http://erj.ersjournals.com/content/50/suppl _61/PA4487.abstract.

Jackson, Sarah E. et al. 2019. "Expenditure on Smoking and Alternative Nicotine Delivery Products: A Population Survey in England." Addiction.

Jiang, Nan et al. 2019. "Perceptions and Use of E-Cigarettes among Young Adults in Hong Kong." BMC Public Health 19(1): 1123. https://doi.org/10.1186/s12889-019-7464-

$\mathrm{z}$.

Kementerian Keuangan. 2017. "Peraturan Menteri Keuangan Republik Indonesia No. 146/PMK.010/2017 Tentang Tarif Cukai Tembakau." : $1-24$. http://www.jdih.kemenkeu.go.id/fullText/2 017/146 PMK.010 2017Per.pdf.

Kementrian Keuangan. 2019. "Peraturan Menteri Keuangan Nomor 152/PMK.010/2019."

Layden, Jennifer E. et al. 2019. "Pulmonary Illness Related to E-Cigarette Use in Illinois and Wisconsin - Preliminary Report." New England Journal of Medicine.

Lichtenberg, Kate. 2017. "E-Cigarettes: Current Evidence and Policy." Missouri medicine 114(5):

335-38. https://pubmed.ncbi.nlm.nih.gov/30228625

Palipudi, Krishna Mohan et al. 2016. "Awareness and Current Use of Electronic Cigarettes in Indonesia, Malaysia, Qatar, and Greece: Findings from 2011-2013 Global Adult Tobacco Surveys." Nicotine and Tobacco Research.

Parekh, Tarang, Sahithi Pemmasani, and Rupak 
Desai. 2020. "Risk of Stroke With ECigarette and Combustible Cigarette Use in Young Adults." American Journal of Preventive Medicine. https://doi.org/10.1016/j.amepre.2019.10.0 08.

Qasim, Hanan et al. 2017. "Impact of Electronic Cigarettes on the Cardiovascular System." Journal of the American Heart Association.

Rasheed, Bello Abdulkadir, Robiah Adnan, Seyed Ehsan Saffari, and Kafi Dano Pati. 2014. "Robust Weighted Least Squares Estimation of Regression Parameter in the Presence of Outliers and Heteroscedastic Errors." Jurnal Teknologi.

Reinikovaite, Viktorija et al. 2018. "The Effects of Electronic Cigarette Vapour on the Lung: Direct Comparison to Tobacco Smoke." European Respiratory Journal: 1701661. http://erj.ersjournals.com/content/early/201 8/01/18/13993003.01661-2017.abstract.

Sihaloho, Estro Dariatno, and Irlan Adiyatma Rum. 2017. "Dampak Ekonomi Dan Kesehatan Pada Konsumen Rokok Elektronik Di Kota Bandung." ISEI Economic Review 1(2): 29 -33.

Sihaloho, Estro Dariatno, and Herlina Silvani Purba Tambak. 2020. "Karakteristik Ekonomi Pada Pengguna Ganda Rokok Elektrik Dan Rokok Konvensional Pada Mahasiswa Di Kota Bandung." EQUILIBRIUM: Jurnal Ilmiah Ekonomi dan Pembelajarannya 8(2): 134-39.

Simonavicius, Erikas, Ann McNeill, Deborah Arnott, and Leonie S. Brose. 2017.
"WhatFactors Are Associated with Current Smokers Using or Stopping E-Cigarette Use?" Drug and Alcohol Dependence.

Slovin, E. 1960. "Slovin's Formula for Sampling Technique."

Stein, Jeffrey S. et al. 2018. "Cigarette and ELiquid Demand and Substitution in eCigarette-Naïve Smokers." Experimental and Clinical Psychopharmacology.

Sussan, Thomas E. et al. 2017. "Electronic Cigarette Use Behaviors and Motivations among Smokers and Non-Smokers." $B M C$ Public Health.

Tejada, Jeffry J, and Joyce Raymond B Punzalan. 2012. "On the Misuse of Slovin's Formula." The Philippine Statistician 61(1): 129-36.

Thoni, H., J. Neter, W. Wasserman, and M. H. Kutner. 1990. "Applied Linear Regression Models." Biometrics.

West, Robert, and Jamie Brown. 2014. "Electronic Cigarettes: Fact and Faction."

The British Journal of General Practice 64(626): 442-43. https://www.ncbi.nlm.nih.gov/pubmed/251 79048.

World Health Organization. 2020. "Strong Legislation Helps Defeat e - Cigarettes in Finland." : 2020.

Yao, Tingting et al. 2017. "Relationship between Spending on Electronic Cigarettes, 30-Day Use, and Disease Symptoms among Current Adult Cigarette Smokers in the U.S." PLoS ONE. 